Review

\title{
The Present and Future Role of Acoustic Metamaterials for Architectural and Urban Noise Mitigations
}

\author{
Sanjay Kumar ${ }^{D}$ and Heow Pueh Lee* \\ Department of Mechanical Engineering, National University of Singapore, 9 Engineering Drive 1, \\ Singapore 117575, Singapore \\ * Correspondence: mpeleehp@nus.edu.sg
}

Received: 25 June 2019; Accepted: 31 July 2019; Published: 1 August 2019

\begin{abstract}
Owing to a steep rise in urban population, there has been a continuous growth in construction of buildings, public or private transport like cars, motorbikes, trains, and planes at a global level. Hence, urban noise has become a major issue affecting the health and quality of human life. In the current environmental scenario, architectural acoustics has been directed towards controlling and manipulating sound waves at a desired level. Structural engineers and designers are moving towards green technologies, which may help improve the overall comfort level of residents. A variety of conventional sound absorbing materials are being used to reduce noise, but attenuation of low-frequency noise still remains a challenge. Recently, acoustic metamaterials that enable low-frequency sound manipulation, mitigation, and control have been widely used for architectural acoustics and traffic noise mitigation. This review article provides an overview of the role of acoustic metamaterials for architectural acoustics and road noise mitigation applications. The current challenges and prominent future directions in the field are also highlighted.
\end{abstract}

Keywords: room acoustics; urban noise; low-frequency noise; indoor noise; traffic noise; acoustic metamaterials

\section{Introduction}

Noise is an integral part of the working environment and can be produced almost everywhere viz. rooms, industries, roads, airports, transportations, etc. In this 21st century, due to extreme exploitation of Mother Nature, noise pollution has become a major issue that affects the health and quality of life especially in the city. Noise was considered as a pollutant for the first time at the World Environment Congress held in Stockholm in 1972 and a recommendation was made for the development of standards for measuring and limiting of noise emissions [1,2]. However, the first modern noise legislation was the U.S. Noise Control Act (NCA) in 1972 [3]. Consequently, the World Health Organization (WHO) published several reports indicating the negative impact of noise on human beings. In 2011, WHO considered noise pollution as one of the most crucial factors having a direct adverse impact on the public health. In this regard, several guidelines have been recommended for safe levels of noise exposure originating from various sources. For example, $<85 \mathrm{~dB}$ in bridge repainting (National Institute for Occupational Safety and Health NIOSH, 1999), the chemical plant ( $<82 \mathrm{~dB}, \mathrm{NIOSH}, 1999)$ [4], railway noise $(<54 \mathrm{~dB})$ [5], aircraft noise ( $<82 \mathrm{~dB})$, etc. More recently, in 2018, WHO set some environmental noise guidelines for public safety in the European region (Table 1). Long exposure to exceeding levels of noise can lead to several adverse human health issues such as, fatigue, stress, hearing loss, high blood pressure, sleeping disorder, psychological disorders, hypertension, obesity, cognitive impairment in children, coronary heart disease, diabetic type I and II, etc. [4,6-9], hence making it imperative to reduce the noise levels. 
Table 1. Recommended safe noise levels for public health safety [5].

\begin{tabular}{ccc}
\hline Source & $\begin{array}{c}\text { Average Noise Exposure } \\
\left(\boldsymbol{L}_{\text {den }}\right) \text { Limit }\end{array}$ & $\begin{array}{c}\text { Night Noise Exposure } \\
\left(\boldsymbol{L}_{\text {night }}\right) \text { Limit }\end{array}$ \\
\hline Road traffic noise & $<53 \mathrm{~dB}$ & $<45 \mathrm{~dB}$ \\
Railway noise & $<54 \mathrm{~dB}$ & $<44 \mathrm{~dB}$ \\
Aircraft noise & $<45 \mathrm{~dB}$ & $<40 \mathrm{~dB}$ \\
Wind turbine noise & $<45 \mathrm{~dB}$ & No recommendation \\
Leisure noise & $<70 \mathrm{~dB} \mathrm{~L}_{\text {Aeq, }} 24 \mathrm{~h}$ & \\
\hline
\end{tabular}

$L_{d e n}$ : Day-evening-night-weighted sound pressure level, over a whole day with a penalty of $10 \mathrm{~dB}(\mathrm{~A})$ for night time noise (22.00-7.00) and an additional penalty of $5 \mathrm{~dB}(\mathrm{~A})$ for evening noise (i.e., 19.00-23.00). $L_{\text {night }}$ : Equivalent continuous sound pressure level when the reference time interval is the night (23.00-7.00).

A variety of traditional materials have been used to reduce noise such as, natural fibers (natural cotton, wool, and kenaf) [10], granular materials (porous concrete, asphalt, and granular clays) [11], synthetic cellular materials (inert glass wool, melamine foams, polyurethane, and polyester) [12,13], mass-loaded vinyl (MLV) [14], etc. These materials are efficient for development of sound absorption systems operating in the high frequency range (Figure 1). The typical sound absorption coefficients of other traditional materials can be found in several handbooks [15-17]. However, in case of low frequency noise $(<200 \mathrm{~Hz})$, these materials often fail to reduce noise effectively. This is because traditional materials follow the mass density law for sound shielding. According to the mass-density law, sound transmission through a substance is given by [18], $T=\frac{1}{\rho \times t \times f}$, where $\rho$ is density, $t$ is thickness of the medium, and $f$ is the sound wave frequency. Sound transmission loss (STL) is calculated as [19], $S T L=10 \times \log _{10}\left[\frac{1}{T}\right]$. Thus, for a particular frequency, doubling the thickness of the sound insulator would result in an increment of only $6 \mathrm{~dB}$ STL. Therefore, a thicker porous material is required for shielding of low frequency noise. This is valid only if the sound source is in "free-field". Moreover, low frequency sound absorbers work using resonance whereas porous absorbers are dissipative media (sound is converted into heat).

Low frequency noise arises from several human-made sources such as compressors, turbines, boilers, automobile engines, aircraft engines, music systems, loudspeakers, etc. Low frequency noise has a very high penetrative power as its dissipative power is quadratic in rate [20,21]. Even a thick concrete wall fails to attenuate low levels of low frequency noise. Researchers have reported several hazardous impacts of low-frequency noise on human health such as annoyance, headache, city-fatigue [22], etc. To attenuate low frequency sound, many composite structures have been demonstrated such as gradient index materials [23], double walls with cladding, perforated plate [24], acoustic mufflers, etc. These composite structures exhibit a group of sound absorbing properties from its constituent or parent materials and are capable of attenuating noise in the mid-to-high frequency range. These are widely used in many application areas such as rooms, auditoriums, offices, and airports. However, sound attenuation at low frequencies remains to be a challenging task because of the inherently weak intrinsic dissipation of traditional homogeneous materials, which usually fail to achieve broadband attenuation in this regime [25].

Owing to the need of low frequency sound absorption, it is desired to develop a new generation of absorbers with deep-subwavelength thickness that can be tailored for a desired frequency spectrum. In the late 1990s, a different kind of functional material known as "metamaterial" was realized, which had the capability of breaking the threshold of inherent properties of tradition sound barriers. Acoustic metamaterials are often made of artificially engineered periodic structures that give rise to unique acoustic wave characteristics, which are not found in nature [26]. Their unusual acoustic properties stem from their geometry and structure rather than the material composition from which they are fabricated. These properties can then be used to control acoustic wave propagation in unprecedented ways. The advent of acoustic metamaterials has revolutionized the concept of sound attenuation in more innovative and effective ways. It offers an entirely different route to further enrich the capability of researchers to design acoustic noise barriers as per specific requirements. By adjusting the geometrical 
size and shape of structures, acoustic metamaterials can be used for noise attenuation purpose over a specific pre-designed and tunable frequency range. The fundamental concept of acoustic metamaterials is extensively discussed in previously published review articles [26-36].

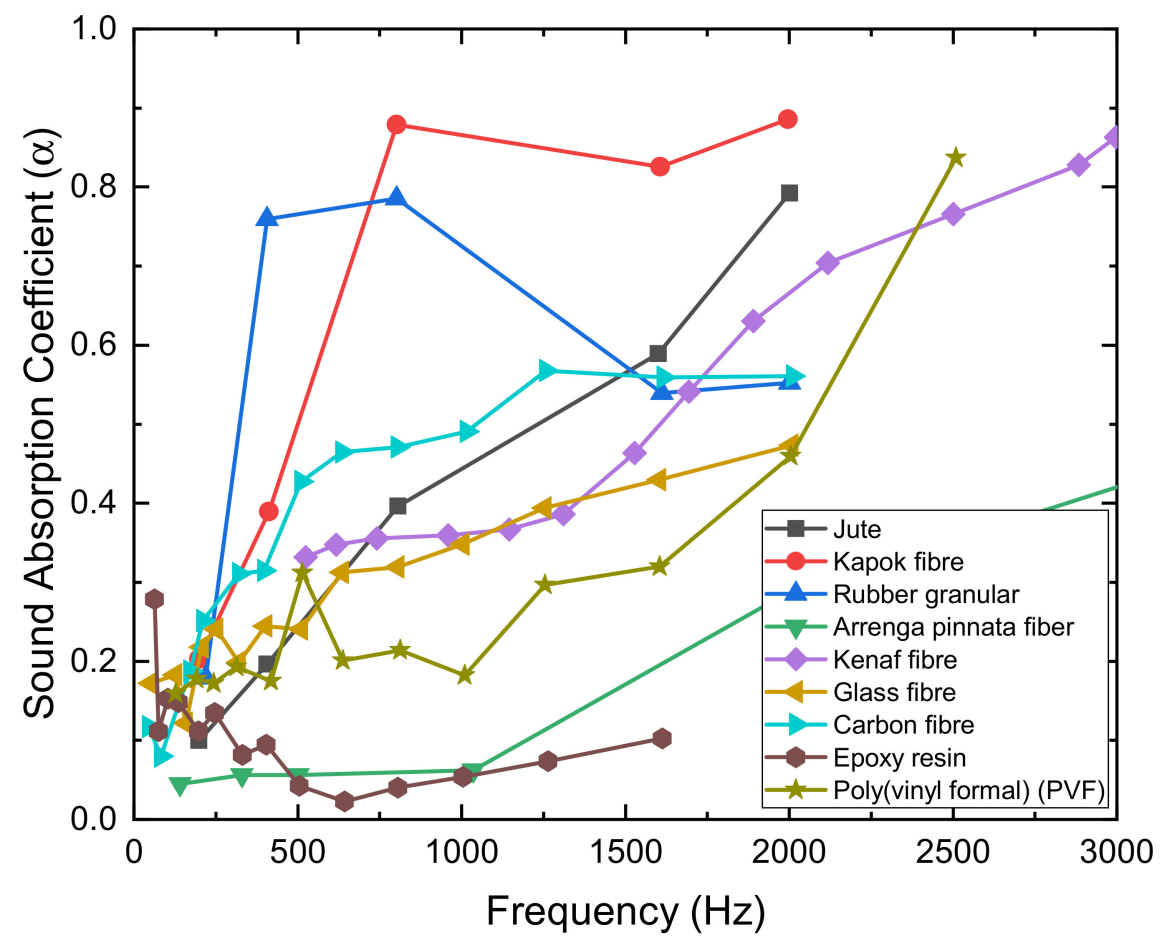

Figure 1. Sound absorption coefficients of various traditional materials. Data are retrieved from the published articles [37-41].

In this article, we have explored the viability of acoustic metamaterials for architectural and urban noise mitigation applications. The fundamental concepts of architectural acoustics, and the crucial factors related to designing of rooms, buildings, etc. are presented in the beginning. Following this, design approaches for acoustic metamaterials, which may be utilized in the mitigation of architectural and road traffic noise are discussed.

\section{Applications of Acoustic Metamaterials}

Noise can be reduced or obstructed by installing different kinds of acoustic metamaterials such as acoustic meta-absorbers, meta-diffusers, sonic crystals, etc. The selection of these noise barriers solely depends on the target requirement. In the following subsection, we discuss the various acoustic metamaterials, which are suitable for low-to-mid frequency noise attenuation.

\subsection{Acoustic Metamaterials as Sound Absorbers}

In the past few years, researchers have demonstrated the efficacy of several hybrid metasurface absorbers, combining the traditional perforated plate with subwavelength-sized metastructures. These acoustic absorbers are based on the concept of impedance-matching of surfaces with hybrid resonance $[42,43]$. When the acoustic impedance of a hybrid metasurface matches with that of the incoming sound wave, the metasurface neither reflects nor transmits the incoming sound wave; it almost perfectly absorbs the incoming sound energy. Cai et al. [44] reported a space coiling-based sound absorbing meta-panel with subwavelength thickness. The structure consists of a coplanar spiral resonant tube embedded in a traditional perforated panel backed by a rigid cavity. Figure $2 \mathrm{a}$ illustrates the design of a unit cell. The designed structure is capable of almost perfectly absorbing the incident sound energy at low frequencies where the impedance of overall structure matches with the 
incoming sound wave. In a physical sense, when the incoming sound wave enters the perforated hole, some portion of the sound wave is absorbed because of three prominent phenomena viz., Helmholtz resonance effect, energy loss due to viscous friction and heat transfer [45]. The remaining sound wave further slows down through the space coiled metastructures inside the air cavity. The space coiling approach is further utilized in designing various other acoustic metamaterials. Li and Assouar [46] proposed an ultrathin acoustic metastructure for perfect sound absorption in the low frequency range. The metastructure consists of a thin perforated plate with centered holes placed on top of a squared rigid air cavity, while a coiled space chamber is sandwiched between them. Figure $2 b$ shows the schematic of the proposed ultrathin acoustic metastructure. Perfect sound absorption is achieved through the proposed metastructure at a frequency of $125 \mathrm{~Hz}$. Jiménez et al. [47] reported a quasi-omnidirectional acoustic meta-absorber with a thickness of deep subwavelength regime $(<\lambda / 88)$. The structure consists of an array of square cross-sectional Helmholtz resonators (HRs) covered with a thin top panel perforated with periodic slits. The incoming acoustic wave enters the cavities of HRs through the slits resulting in an effective sound wave attenuation in a low frequency regime. Figure $2 \mathrm{c}$ shows the conceptual view of the thin panel placed on a rigid wall with an array of Helmholtz resonators. The proposed metastructure was also fabricated for experimental measurements. As shown in Figure 2c; right, almost perfect absorption $(\alpha=0.97)$ is achieved experimentally at $338.75 \mathrm{~Hz}$. This metastructure is highly tunable, and its local resonance can be tuned by adjusting the geometrical variables. Recently, Tang et al. [48] presented a honeycomb-corrugation hybrid core (H-C hybrid core) acoustic metamaterial for sound absorption in the low-frequency regime. The metastructure consists of two face sheets, a lightweight perforated top plate and a rigid panel as bottom face sheet while, a sandwich perforated honeycomb-corrugation hybrid core is sandwiched between two sheets. Figure $2 \mathrm{~d}$ shows the schematic of the proposed metastructure. The proposed metamaterial exhibits a broadband sound absorption and also possess high mechanical stiffness/strength.

\subsection{Acoustic Metamaterials as Sound Barriers}

In recent years, several types of acoustic metamaterials have been reported for environmental noise mitigation showing the potential for scale-up. In early stages, membrane type metamaterials were popular for low frequency noise attenuation and showed tremendous potential for several applications like indoor noise, aircraft cabin noise mitigation [49-52]. Kumar et al. [53,54] demonstrated a membrane type double negative acoustic metamaterial for low frequency noise attenuation. The structure consists of periodically arranged unit cells, with each unit cell comprising two hexagonal cavities interconnected with a cylindrical hollow neck and an elastic membrane stacked on both ends. Figure 3a illustrates the geometrical design of the proposed metastructure. A wide band gap was achieved due to a strong coupling between the membranes and the hexagonal Helmholtz resonators. An average sound transmission loss of $45 \mathrm{~dB}(\mathrm{~A})$ was attained for frequencies below $500 \mathrm{~Hz}$, which satisfactorily agree with the NIOSH standards. Figure $3 \mathrm{~b}$ shows the transmission loss spectra obtained from the double negative acoustic metastructure. Membrane type metamaterials are associated with some limitations like variation of membrane properties in environmental conditions, requirement of external equipment for membrane holding, air leakage due to poor adhesion between membrane and metastructures, manufacturing challenges in large size membrane production, etc. Recently researchers have tried to address these challenges by replacing the elastic membrane with a stiff thin polymeric plate [55-57]. Ang et al. [58] reported a large-scale plate type acoustic metamaterial for low-frequency noise control. The structure consists of two Mylar thin plate sheets and an internal tonraum resonator, assembled with two rigid outer frames. The incoming sound enters the metastructure through a small orifice provided onto the plate. Figure $3 \mathrm{c}$ depicts the schematics of the proposed unit cell. The acoustic performance of the proposed metamaterial is superior to existing commercial noise barriers. Furthermore, the plate type metamaterial is relatively simple to scale up for real applications. 
(a)
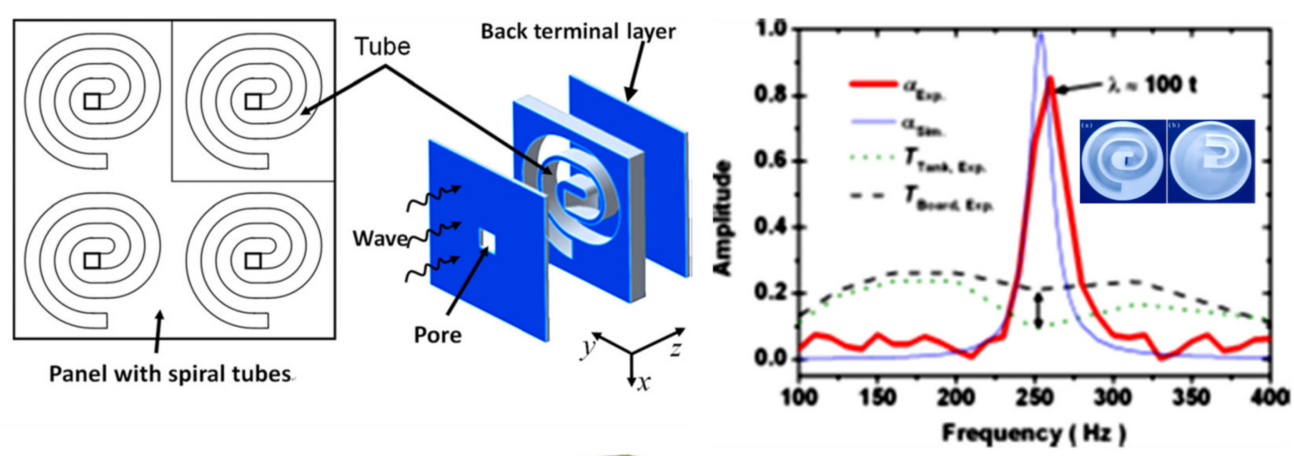

(b)

(c)
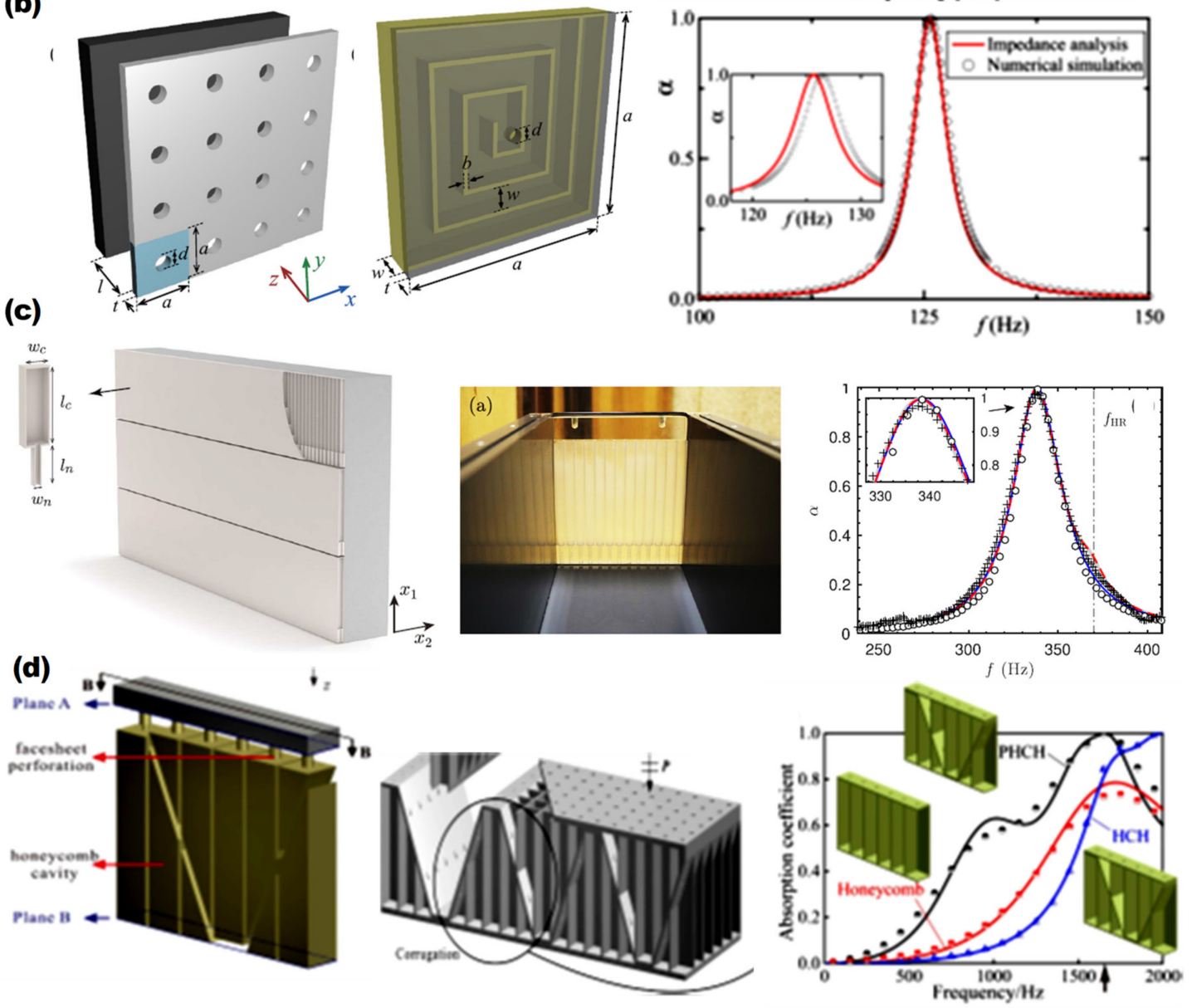

Figure 2. (a) Schematic of space coiled metamaterials (left) and sound absorption plot (right), Inset shows the 3D printed unit cell. Reprinted with permission from Cai et al. [44], (C) 2014 AIP Publishing LLC; (b) schematic diagrams of the metasurface composed of a traditional perforated plate (transparent gray region) with a hole and a coiled air chamber (left). Simulated sound absorption coefficient results (right) of the proposed metasurface. Reprinted with permission from Li and Assouar [46], (C) 2016 AIP Publishing LLC; (c) schematic presentation of ultra-thin acoustic metamaterials (left), photograph of installed fabricated structure for experimentation (center) and measured absorption coefficient of the system (right). Reprinted with permission from Jiménez et al. [47], (C) 2016 AIP Publishing LLC; (d) schematic diagrams of proposed hybrid acoustic metamaterials, comprising of a perforated plate and AMs (left), sound absorption coefficient of hybrid acoustic metamaterials compared with competing structures (right). Reprinted with permission from Tang et al. [48], licensed under a Creative Commons Attribution 4.0 International License. 
(a)
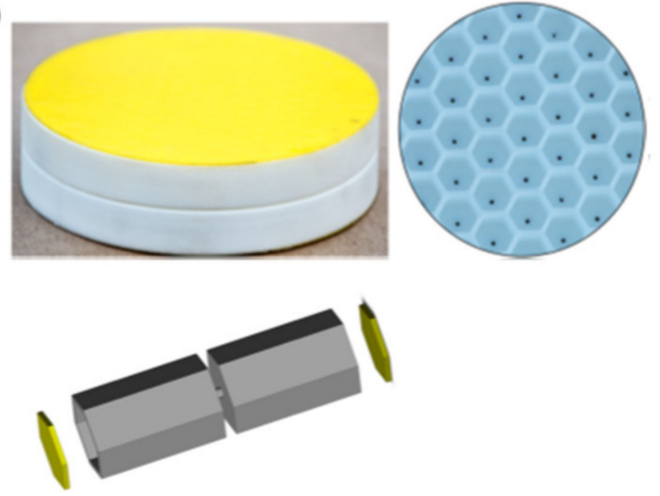

(c)

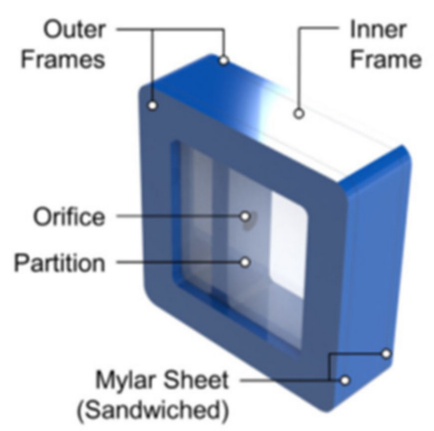

(b)
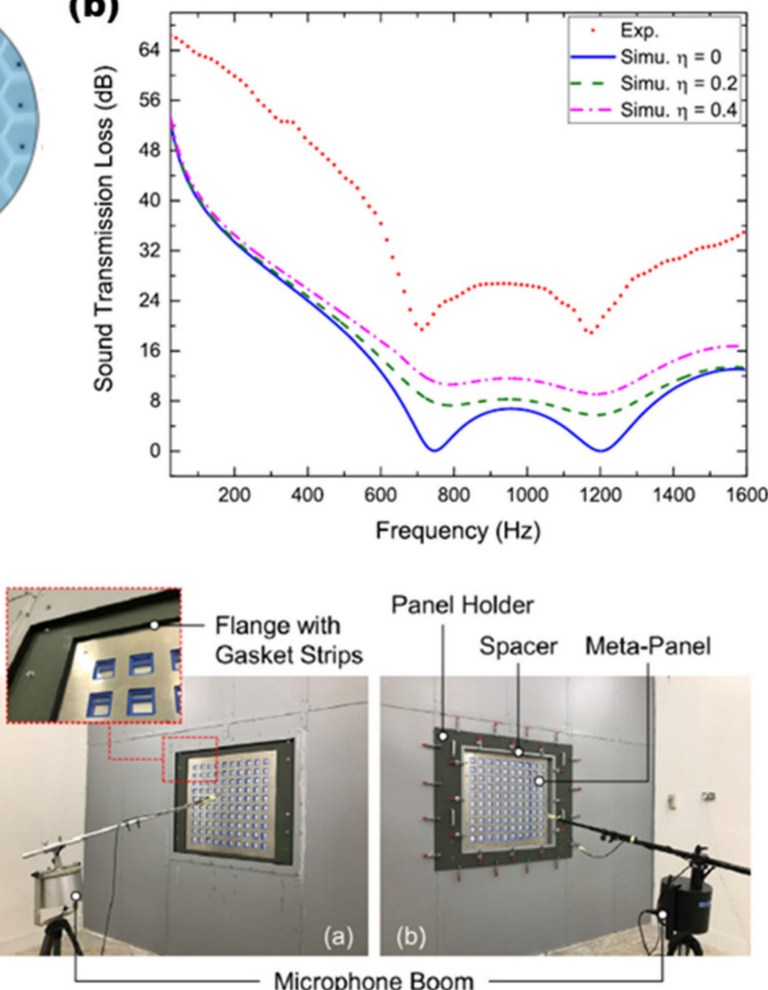

Figure 3. (a) Schematics of double negative acoustic metamaterial; (b) measured and simulated sound transmission loss of the proposed metamaterials. $a$ and $b$ are reprinted with permission from Kumar et al. [53], (C) 2018 AIP Publishing LLC; (c) schematic of plate-type acoustic metamaterial (left) and reverberation room setup for transmission loss measurement of the large size metamaterial (right). Adapted with permission from Ang et al. [59], (C) 2019 Elsevier Ltd.

Another type of sound barriers, sonic crystals, have been widely used for the outdoor noise mitigation. The basic idea of sonic crystals conceived from the concept of photonic crystal-a refraction index-modulated periodic structures, used for manipulation of an optical wave. Sonic crystals are non-homogeneous composite structures comprising of a regular distribution of wave scatterers distributed in 3D space, whose material properties like elasticity and density differ from those of the host medium $[60,61]$. The size of a sonic crystal is on a deep subwavelength scale so that at specific frequencies (mid-gap frequencies), the band gap structure obstructs the incoming acoustic waves while, at frequencies away from the resonances, the composite structure allows acoustic waves to pass through it displaying weak wave scattering [62]. Some critical parameters mostly influencing the size of the band gap are the density ratio-the ratio between the densities of scatterer's material and that of host medium, the filling factor-the volume fraction occupied by the scatterers and the lattice designs [63], so the band structure of a sonic crystal can be engineered and tuned by adjusting the above parameters. A variety of shapes such as spherical [62], cylindrical [64], square [65], triangular [66], rectangular [67] and honeycomb [68] are used to make these lattice scatterers. The spacing between two consecutive scatterers is chosen such that the periodic structures interact with the incident wave efficiently. The Bragg's law governs the distance between two adjacent scatterers $(\delta)$ for destructive interference of a wave, which is as follows, $f=c / 2 \delta \sin \theta$, where $\mathrm{f}$ is the center frequency of the bandgap, $c$ is the speed of sound and $\theta$ is the incident angle of incoming sound wave relative to the front plane of the array of scatterers. Therefore, the band gap frequency can also be tuned by varying the distance between the scatterers. In the past few decades, researchers have reported several innovative metamaterials based on sonic crystals for sound insulation purposes. Among these, some of the structures have shown great potential for indoor noise attenuation as well as outdoor noise. 
Morandi et al. [69] developed a real-sized sonic crystal and successfully installed it as a noise barrier in the Acoustic Laboratory of the University of Bologna. The structure is made of hollow PVC cylinders periodically arranged in a square lattice. Figure 4a shows the photograph of a fabricated sonic crystal for experimental measurements. Each vertical cylinder has a length of $3 \mathrm{~m}$, the outer radius of $0.08 \mathrm{~m}$ and annular thickness of $3.2 \mathrm{~mm}$. The width of the proposed sonic crystal noise barrier is $3 \mathrm{~m}$ wide, and its depth varies as per the number of rows of cylinders. They performed several acoustical measurements of the sonic crystal with different depths. Figure 4 (a, bottom) shows the measured sound insulation index at varying number of rows of cylinders. As the traffic noise spectrum is centered around $1000 \mathrm{~Hz}$, the proposed structure is suitable for outdoor noise mitigation. Recently, Lee et al. [70] designed and developed a new kind of structure for both indoor and outdoor noise attenuation in the low-to-mid frequency range. The structure is comprised of an array of rectangular sonic crystals. Figure $4 \mathrm{~b}$ shows the basic design of the sonic crystals. They performed several acoustical experiments in different environmental settings such as indoors, windows, outdoors, etc. for calculation of sound insertion loss of the proposed structure and validated their potential applicability. Following this work, their group designed several variants of sonic crystals such as the serrated trailing edge of ceiling fan blades [71], sonic crystal window [72] and ventilated plenum window [73]. More recently, Cavalieri et al. [74] presented a 3D locally resonant sonic crystal for broadband noise attenuation. The metastructure is made of square shaped scatterers containing periodically arranged two different kinds of resonators namely, quarter wavelength resonators and Helmholtz resonators. Figure $4 \mathrm{c}$ shows the schematic diagrams of both the resonators and three-dimensional unit cell. The hybrid resonators yield multiple coupled resonant frequencies and the Bragg bandgaps exhibiting a sound insertion loss of about $16.8 \mathrm{~dB}$ in a wide band gap ranging from 350 to $5000 \mathrm{~Hz}$ (Figure 4d). The structure is suitable for railway noise mitigation.

Recently, acoustic metadiffusers are reported for noise shielding purposes. The acoustic metadiffusers are based on a classic design "Schroeder diffuser" used for desired sound reflection in a diffuse field. Since its first discovery in the late 1970s [75,76], the Schroeder diffuser (SD) has been used for controlling the acoustic energy level in many indoor applications like rooms, concert halls, large auditoriums, opera houses, etc. where substantial loss of sound energy is undesirable. These traditional diffusers are generally composed of a series of wells of different depths designed for the desired sound scattering. The depth of wells is based on the number sequence theories [75], and the overall thickness is selected according to a specific sound frequency. Figure 5a shows the basic representation of well design, so Schroeder diffusers are bulky in size, especially for low-frequency sounds such as traffic noise or human voices, the thickness of a diffuser could reach an exceptional value of $69 \mathrm{~cm}$ at $250 \mathrm{~Hz}$, which limit their installation in real settings. In recent times, researchers have redesigned the diffusers by incorporating the concept of acoustic metamaterials with existing SDs. Zhu et al. [77] presented an ultrathin acoustic metadiffuser whose performance is almost similar to the conventional diffuser but with a 1/10th of thickness. The metadiffuser consists of a two-dimensional array of locally resonant wells with a single Helmholtz resonator like structure at the bottom (Figure $5 b$ ). The diffusion coefficient spectra of the proposed structure are presented in Figure $5 \mathrm{c}$.

Jiménez et al. [78] designed and fabricated the metadiffusers with deep-subwavelength thickness in a range of $1 / 46$ th to $1 / 20$ th times the designed wavelength. The modified diffusers were designed for frequencies ranging from $250 \mathrm{~Hz}$ to $2 \mathrm{kHz}$, and composed of seven sub-wavelength slits, each of them consisting of three Helmholtz resonators (Figure 5d). The Helmholtz resonators display a strong dispersion, reducing the speed of sound inside the cavities, and hence each slit behaves like a deep-subwavelength resonator. By tuning the geometries of the metadiffusers, broadband reflections in a desired frequency range can be achieved. Following these works, several metamaterial-based diffusers have also been reported [79]. These structures have a potential for commercialization and can be an alternative solution to the existing bulky and ineffective noise barriers. 
(a)
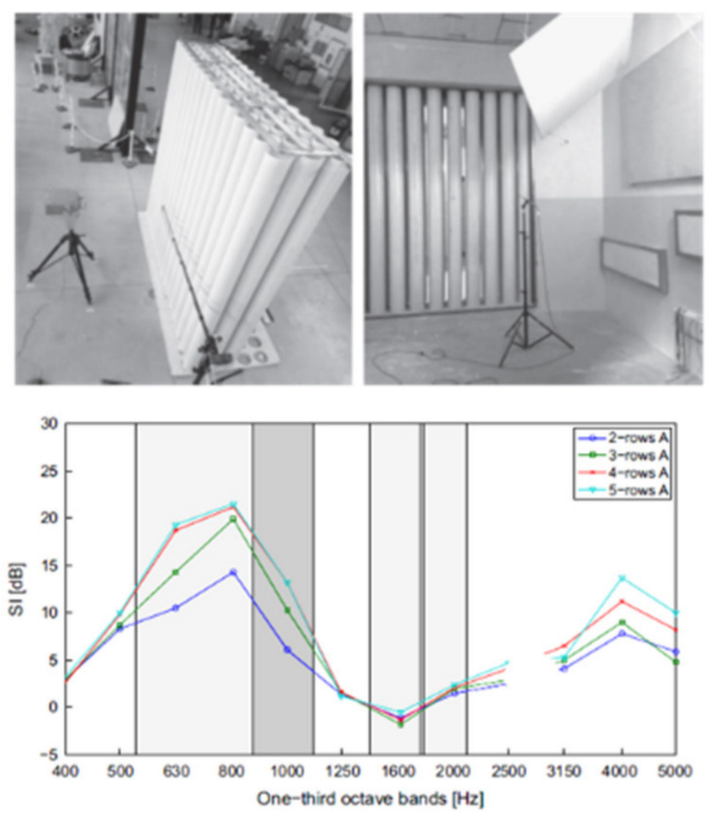

(c)

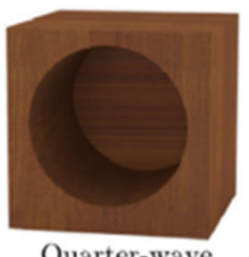

Quarter-wave

(d)
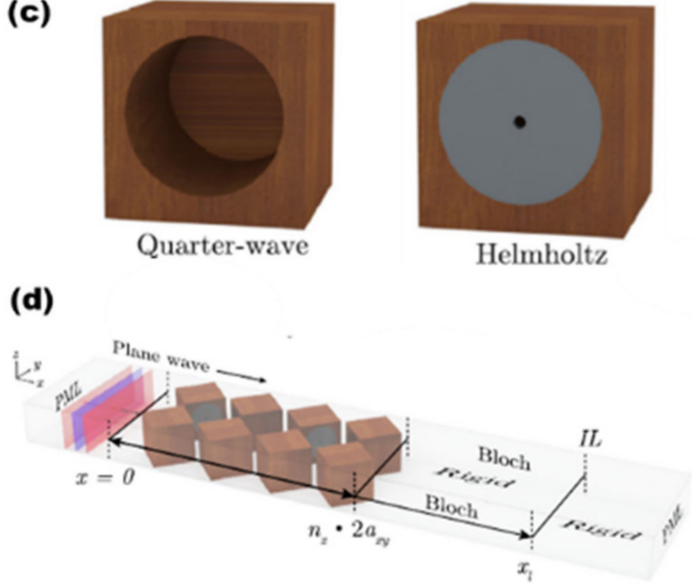

Helmholtz (b)
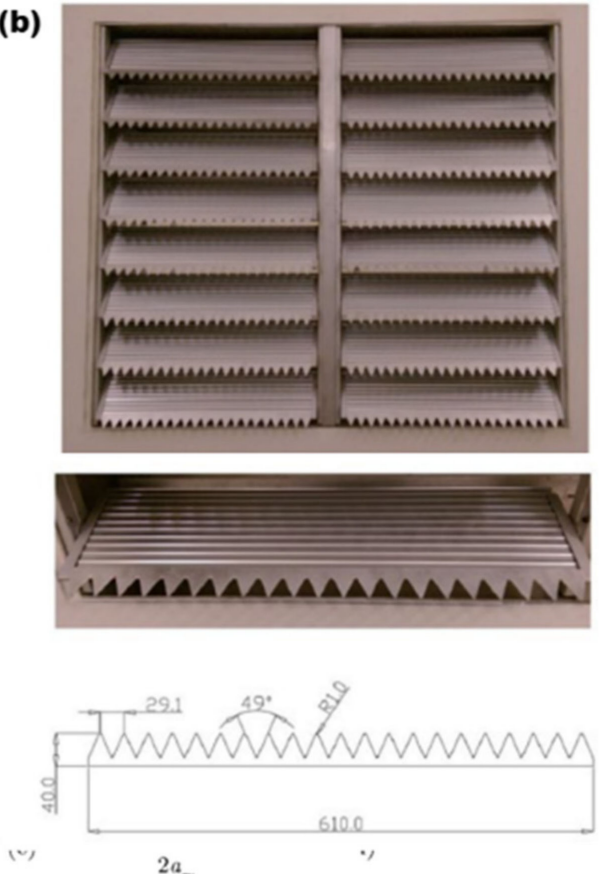

(v)

$2 a_{n}$
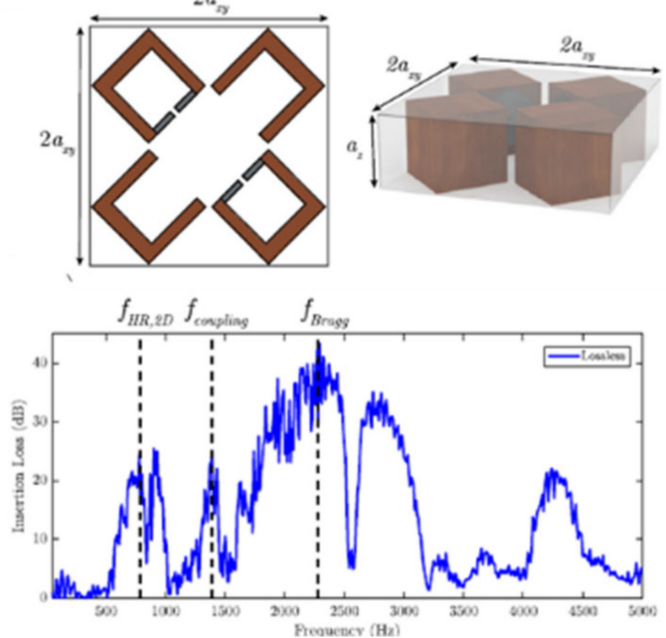

Figure 4. (a) Experimental setup for the measurement of sound insulation index (left) and sound reduction index (right) of the sonic crystal. The sample was arranged in the main hall (volume $5000 \mathrm{~m}^{3}$ ) of the laboratory. Measured values of sound insulation index of the sonic crystals (bottom). The central microphones were placed such that the microphone array faces the center of a cylinder. Reprinted with permission from Morandi et al. [69], (C2016 Elsevier Ltd; (b) photograph of rectangular sonic crystals employed as a ventilated window. The unit cell of sonic crystal window with dimensions (bottom); (c) schematic diagram of the unit cell: Local resonators (quarter wavelength and Helmholtz resonator) and a three-dimensional unit cell; (d) layout of insertion loss measurement (left) and the measured insertion loss plot (right) in the real railway noise environment. Reprinted with permission from Cavalieri et al. [74], ()2019 Elsevier Ltd. 
(a)

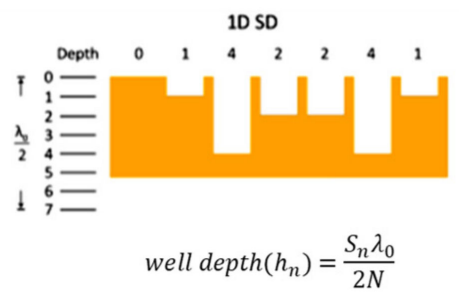

(c)

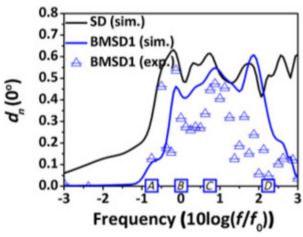

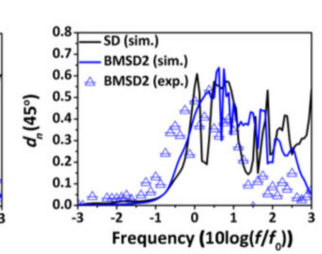

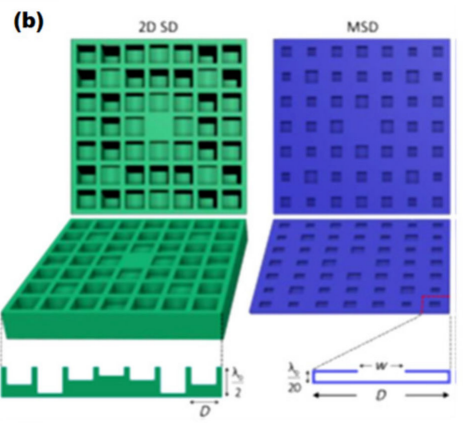

(d) Metadiffuser

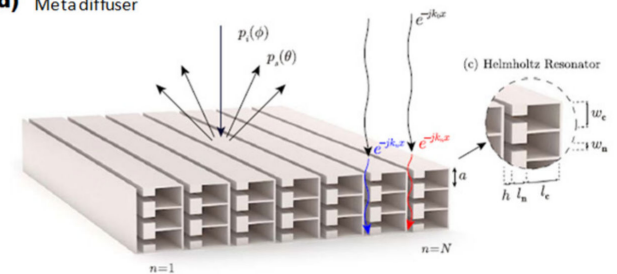

Figure 5. (a) Schematic representation of one dimensional Schroeder diffuser with seven wells. The well depth $\left(h_{n}\right)$ nth well is calculated from the above-mentioned formula. Where $S_{n}=n^{2}$ moduloN; is the sequence number for the nth well. Here, modulo indicates the least non-negative remainder and $N$ is the number of wells per period. $\lambda_{0}$ is the wavelength; (b) schematics of a 2D Schroeder diffuser (SD; left) and the proposed metasurface-based SD (MSD) with their unit cells; (c) simulated and measured diffusion coefficient $\left(d_{\mathrm{n}}\right)$ spectra for normal incidence (left) and $45^{\circ}$ incidence (right) in the $\mathrm{x}-\mathrm{z}$ plane versus frequency for the broadband MSD (BMSD) and the conventional SD, respectively. Figure a, $\mathrm{b}$ and $\mathrm{c}$ are reprinted with permission from [77], published by the American Physical Society under the terms of the Creative Commons Attribution 4.0 International license; (d) scheme of metadiffuser composed of seven slits, containing three Helmholtz resonators in each of the slits. Reprinted with permission from [78], published by the Springer Nature under the terms of the Creative Commons Attribution 4.0 International License.

\subsection{Acoustic Metamaterials as Soundproof Ventilated Windows}

A ventilated window is generally used for circulation of fresh air from the external environment into a room, but at the same time, unwanted outdoor noise travels through these vents. At times, the noise may amplify due to the architectural structure of the vents. Several traditional approaches like installation of noise barrier mats in front of the window, and use of sound absorbing materials for the fabrication of the entire window are used to reduce the noise levels. However, the problem persists, because these techniques are not adequate for low-frequency noise mitigation. Addition of auxiliary materials also result in a bulky structure, occupying substantial spaces, and restricting the air flow, which is extremely undesirable for small buildings. In the past few years, researchers have come up with unique designs of metamaterial-based windows for mitigation of outside noise in a wide band gap. The metastructures exhibit several desirable characteristics like lightweight, deep subwavelength thickness, highly tunable and can be easily fabricated using 3D printing.

Kim and Lee [80] presented an air transparent (air ventilation) soundproof window for the low-to-mid frequency noise mitigation. The structure consisted of a three-dimensional array of resonators with a centered hole in each resonator (Figure 6a). The air hole and rooms were separated by an automotive air filter made of sound dissipative material. The cylindrical hole allowed air circulation while resonator dampened the incoming sound wave in a particular frequency range. The sound attenuation of the structure is based on the theory of wave diffraction and the concept of "impedance matching". A large size window of $1.2 \mathrm{~m} \times 1 \mathrm{~m}$ is fabricated to measure the transmission loss in an anechoic chamber. The result shows a significant transmission loss of 20-35 dB in the range of 700-2200 Hz (Figure 6a). Yu et al. [81] demonstrated the sound transmission capabilities of a periodic acoustic metamaterial 
grating of finite size. Figure $6 \mathrm{~b}$ shows the schematic of a single layer periodic acoustic metamaterial grating. Each metamaterial unit cell consists of an open duct patterned with the coiled resonators. The sound transmission behavior of the structure is mainly governed by the acoustic stop-band, the edge diffraction and the radiation interference behind the acoustic grating. A maximum transmission loss of $40 \mathrm{~dB}$ is achieved through the structure signifying its potential for future applications. Jung et al. [82] presented a muffler type acoustic metamaterial panel for ventilated sound attenuation. As shown in Figure $6 c$, each unit cell of the metapanel consisted of one circular duct enclosed by an array of annular cavities. The air duct allows for the air passage while the incoming sound wave is attenuated due to the acoustic impedance mismatch at the intersection between the circular duct and the annular cavity. Wu et al. [83] designed and fabricated a ventilated metamaterial absorber with an operating frequency of $<500 \mathrm{~Hz}$. The structure is composed of periodically arranged multiple unit cells. Each unit cell consists of two identical but oppositely oriented split tube resonators (Figure $6 \mathrm{~d}$ ). The gap between two adjacent unit cells allows air to flow through the structure. The high absorption of the sound wave has resulted from the weak coupling of two split tube resonators. A 3D printed sample is fabricated from polylactide (PLA) plastic for the experimental measurements (Figure 6d). The experimental result shows the maximum sound absorption of $82.1 \%$ at $342 \mathrm{~Hz}$ and no significant change in absorption under the oblique incidence (up to $60^{\circ}$ ). Shen et al. [84] presented the two-dimensional ventilated acoustic metacages with a subwavelength thickness (Figure 6e). A ring-shaped structure is created by the radial arrangement of the metacages, and each metacage is composed of several shunted Helmholtz resonators with increasing heights along the radial direction. The structure is capable of shielding the noise coming from all directions while allowing substantial airflow through a gap between two adjacent metacage. An omnidirectional acoustic shielding is realized by the fabricated structure. Li et al. [85] demonstrated a broadband compact acoustic absorber for the low-to-mid frequency noise absorption while ensuring high ventilation for air passage. The structure is constructed by attaching the eight unit cells to the outer periphery of the square-shaped hollow tube. Each unit cell consists of a double-layered metastructure with micro-perforated holes on opposite sides. Figure $6 \mathrm{f}$ shows the schematics of the proposed absorbers. The perforated unit cells serve for the sound attenuation while the hollow tube provides the passage for air ventilation ( $70 \%$ cross-section open). They experimentally showed the high absorption (>0.5) in the frequency range of $850-1000 \mathrm{~Hz}$.

Recently, Ghaffarivardavagh et al. [86] demonstrated a prototype of ring-like ultra-open acoustic metamaterial with capabilities of silencing the incoming sound as well as allowing the air to pass through it. Figure $6 \mathrm{~g}$ shows a 3D printed ring-like acoustic barrier. The design is based on Fano-like interference for effective sound attenuation at a desirable frequency. As shown in Figure $6 \mathrm{~h}$, the metastructure almost reflects the incoming sound (94\%) to the environment. Their unique design has great potential for real applications like window frame for rooms, where both effective sound attenuation and proper air ventilation are required.

More recently, researchers have demonstrated asymmetric acoustic metamaterials possessing unique characteristics like unidirectional sound wave propagation. These kinds of structures allow air circulation inside the building, and at the same time, restrict outside (omnidirectional) noises. Zhang et al. [87] proposed an omnidirectional ventilated acoustic barrier with a planer profile and a subwavelength thickness (Figure 7a). The barrier is composed of multiple arrays of unit cells with two different structures, a hollow pipe and a labyrinthine (coiled unit). The hollow unit cell allows the uninterrupted transmission of fluid and other entities like light, while the labyrinthine unit cell blocks the omnidirectional noise. Figure $7 \mathrm{~b}$ shows the sound transmission spectra of both unit cells. As shown, hollow pipe unit cell allows constant sound transmission (unity) over the frequency range, and on the other hand, a coiled unit cell has a transmission peak at the resonant frequency of $5600 \mathrm{~Hz}$, and after that, it decreases. The acoustic barrier is capable of obstructing sound with random incident angles (ranging from normal incidence to grazing incidence) while providing high ventilation (63\% ventilation rate). Ge et al. [88] presented an open window structure exhibiting the unidirectional acoustic insulation properties. The open window is constructed by assembling the multiple blades attached with a unique metasurface. Each metasurface is composed of a periodic array of hook-like meta-atoms (Figure 7c). 
During the sound wave propagation through the open window, the lateral momentum of acoustic wave changes due to the hook-like meta-atoms, which leads to an acoustic blind region. Figure $7 \mathrm{~d}$ shows the schematic configuration of the assembled window with wave directions. As shown in figure, in the frequency range of $2.89-3.51 \mathrm{kHz}$ (shadow region), the sound transmission coefficient (simulated) is less than 0.2 for the right-side incidence (RI) while for left-side incidence (LI) is higher than 0.9. For the experimental realization of these unusual properties, metastructure was fabricated using 3D printing techniques, and the sound transmission was measured for LI and RI. The experimental results show a good agreement with simulation results (Figure 7e). Following this work, they demonstrated the switchable omnidirectional acoustic insulation capabilities of the same metastructures [89]. The sound propagation direction of the open window structure can be switch by merely changing the configuration of the meta-atoms array. Sound insulation can also be switched "on" or "off" by adjusting the distance between two adjacent blades, i.e., tunnel gap. These studies indicate that sound transmission can be flexibly tuned as per the requirements and has great potential for future applications.

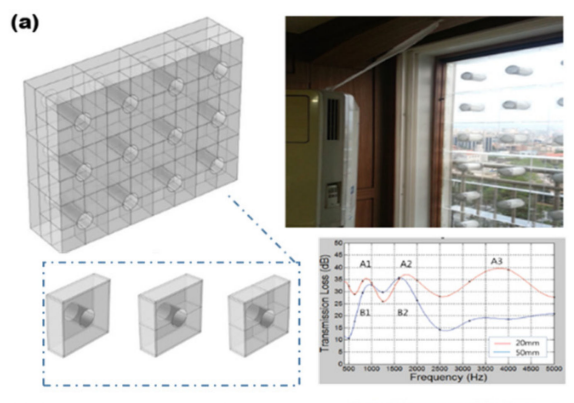

(d)
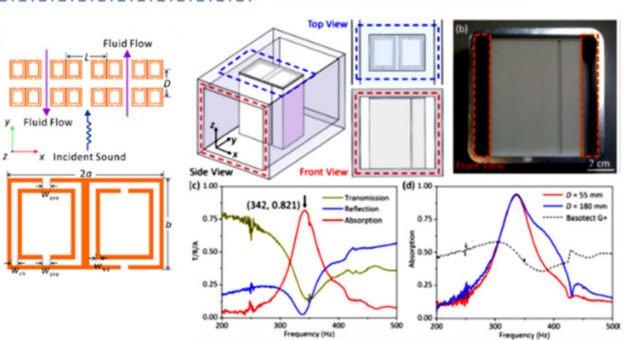

(f)

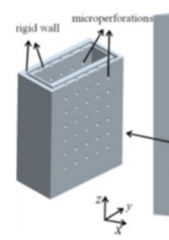

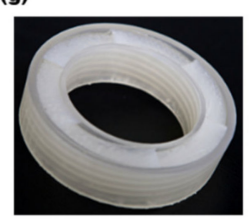

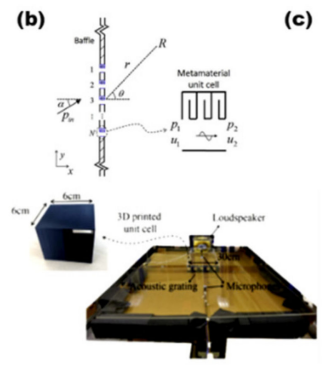

(c)

(e)
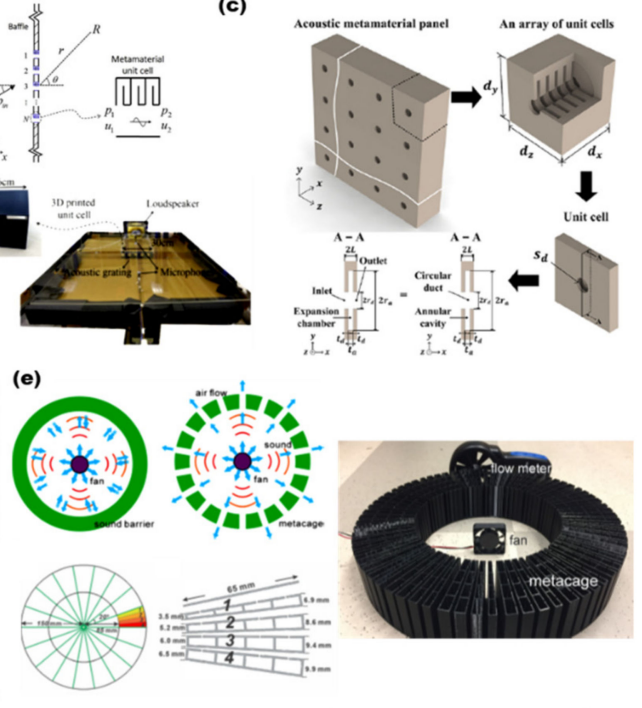

(h) '

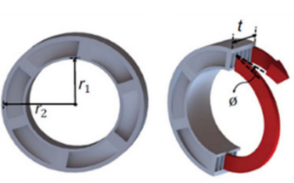

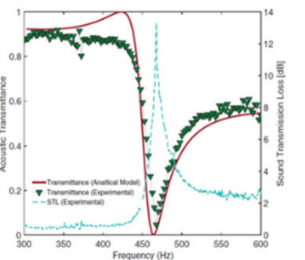

Figure 6. (a) Schematics of the air transparent soundproof window (left top), consisting of three different unit cells, namely, one, two, and four rooms (left bottom). Fabricated window installed near a highway (right top), and measured transmission loss of windows with different dimensions (right bottom). Reprinted with permission from [80], (C2014 Author(s); (b) schematic of a single layer periodic acoustic metamaterial grating. Reprinted with permission from [81], (C) 2019 Elsevier Ltd; (c) schematic representation of the proposed acoustic metamaterial panel, comprising of an array of unit cells, the unit cell of which consists of a circular duct (i.e., a circular hole) and an annular cavity. Reprinted with permission from [82], (C) 2018 Author(s); (d) geometrical illustration of the designed ventilated metamaterial absorber (left). Experimental setup for the transmission loss and absorption coefficient measurements of the fabricated sample (right top). Reprinted with permission from [83], (C) 2018 Author(s); (e) schematic of the metacage (left bottom) with the geometry of each unit cell. Experiment set-up of the flow rate measurement (right). Reprinted with permission from [84], (C 2018 Author(s); (f) 3D schematic diagram of the proposed broadband compact absorber. Reprinted with permission from [85], (C) 2018 Author(s); (g) Schematics of ultra-open acoustic metamaterial silencer and a 3D printed circular unit cell; (h) acoustic transmittance and sound transmission plot of the proposed metastructure. Figure $f$ and $g$ are reprinted with permission from [86], (C2019 American Physical Society. 
(a)

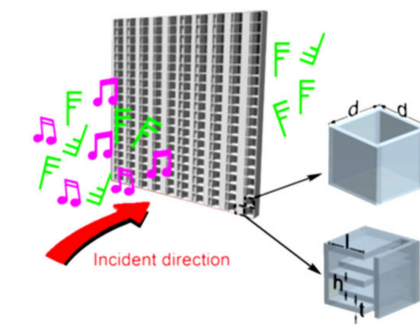

(c)

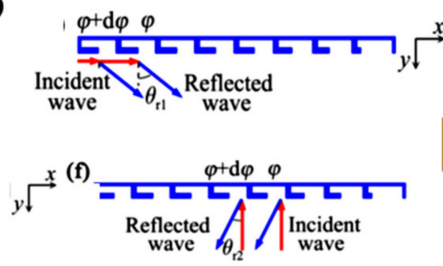

(d)

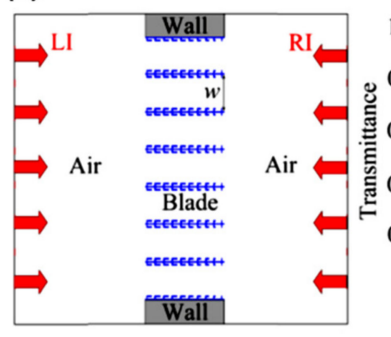

(b)
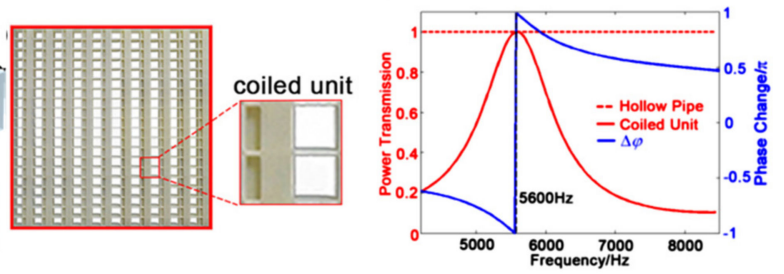

(e)
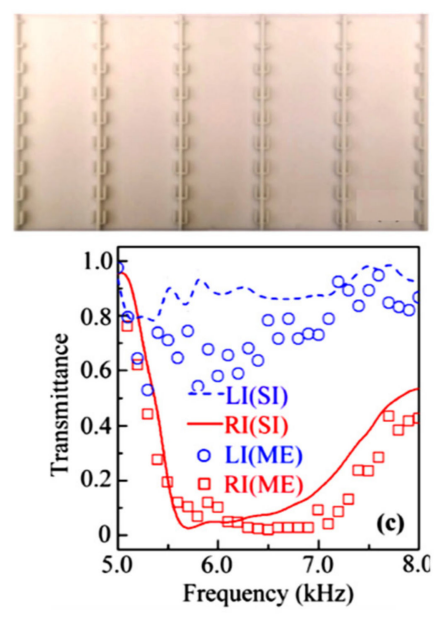

Figure 7. (a) Schematic of the omnidirectional ventilated acoustic barrier, consisting of two unit cells with different structural outlines. The wind signal represents the wind, and the "note" represents the acoustic wave in both sides of the planer surface. Photograph of a 3D printed fabricated acoustic barrier; (b) transmission spectra of the coiled structure, hollow pipe and phase delay of the resonant unit versus frequency. Figure a and b are reprinted with permission from [87], (C) 2017 Author(s); (c) schematic of an acoustic metasurface with hook-like meta-atoms; (d) schematic of unidirectional acoustic insulation (UAI) window composed of six blades and transmittance spectra for left-side incidence (LI) and right-side incidence (RI); (e) photograph of unidirectional acoustic insulation window (top) with simulated and measured transmission spectra (bottom). Figure c, d and e are reprinted with permission from $[88,89]$ ] 2018 Author(s), and (C)2019 American Physical Society, respectively.

\section{Challenges and Future Outlook}

In the past 20 years, a lot of progress has been made in the field of acoustic metamaterials, displaying their tremendous potential for low-to-high frequency noise mitigation. However, their practical implementation is still in a nascent stage. Recently, Sonobex Ltd. United Kingdom, launched the first commercially available acoustic metamaterial-based noise barrier $[90,91]$. The structure is composed of multiple unit cells. Each unit cell is a hollow, elongate structure consisting of four rigid walls made of either metals or polymers. These walls are arranged to form a trapezoidal cross section. Figure 8a shows a schematic of an acoustic attenuator unit cell, while Figure $8 \mathrm{~b}$ shows the photograph of an acoustic screen for noise shielding.

Owing to the advancement in technology, the designs developed by the researchers in this field can be implemented in practical settings as tiles or bricks, for building soundproof permeable walls. However, the laboratory-based proof-of-concept structures may not always well suited to real-world applications [28]. Since the large-scale fabrication of acoustic metamaterials is still a challenging task for manufacturers [92]. This requires engineers to think beyond the traditional fabrication techniques. Currently, 3D printing is the most commonly used fabrication technique for acoustic metamaterials. However, 3D printing is not yet a sustainable mass production technology and hence is expensive. Some emerging hybrid manufacturing techniques may provide a viable alternative to the current $3 \mathrm{D}$ printing 
technology. Recently, Bishop-Moser et al. [92] have investigated the challenges and opportunities facing metamaterials manufacturing and stated a set of recommendations for realizing the assured impact. Among these, two key recommendations are first, establish a national metamaterials manufacturing research initiative to enabling the scaling of process technologies for the fabrication of metamaterials, including, pattern transfer, self-assembly and 3D printing. Another recommendation is to establish an interdisciplinary advisory group, which can put an effort in future roadmap of metamaterials manufacturing technology research.

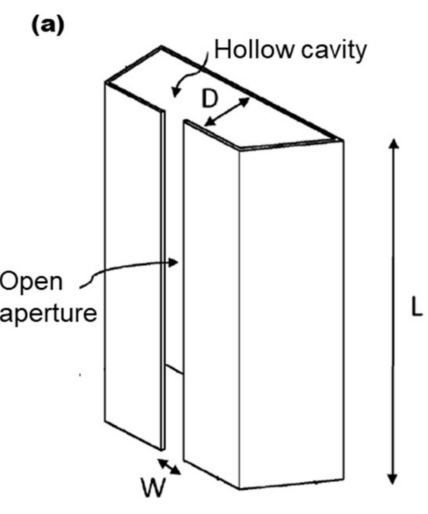

(b)

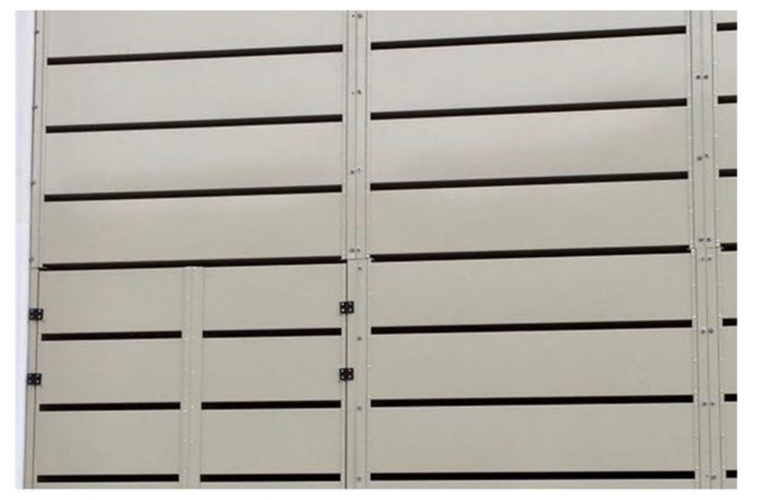

Figure 8. (a) Perspective view of an acoustic attenuator consisting of four walls, a hollow and elongate body of length L and an open aperture of width W [90]; (b) photograph of the acoustic screen with the NoiseTrap@technology, installed as a door of the transformer room. The technology is developed by @Sonobex Limited, United Kingdom [91]. The photograph is taken from the website: https://www. sonobex.com/portfolio-item/substation-transformer-noise/ (accessed on 16 June).

Another major challenge is the effective assessment of noise in an environment where sound sources vary randomly (traffic, airport, auditorium and other public places). An inaccuracy in noise assessment may result in the installment of acoustic metastructures with an incorrect design. An emerging alternative to this problem is the development of active acoustic metamaterials, which can be deployed for variable noise attenuation [93-96]. Moreover, environmental factors such as temperature and humidity should also be considered during the development of acoustic metamaterials for outdoor applications. The environmental factors affect the sound propagation behavior [97,98]. The elastic membrane may also lose their inherent material properties under long exposure of high temperature, affecting the acoustic performance of the membrane-type metamaterials. Besides, most of the acoustic metastructures involve complex geometrical structures with small size, and their acoustic performance heavily relies on these sophisticated features. In a polluted environment, regular maintenance is essential to keep these metastructures functional. By addressing the above issues in the future, acoustic metamaterials can play a significant role in developing noise silencers and barriers for both architectural and urban noise. In the current scenario, materials with multi-functionality are of a great demand. Hence, along with sound mitigation, acoustic metamaterials may be designed simultaneously for other applications like energy harvesting, environmental temperature dampening or shielding, air filtration, etc. For example, through an acoustic energy harvester, the entrapped acoustic energy entrapped during the noise mitigation process is converted into electrical power. Generally, a piezoelectric bimorph with the acoustic metamaterials is used for energy conversion. Based on this concept, several works have been reported [99-102]. Although the extracted electrical energy is on a minute scale, it may be improved further in the future with more innovative designs. In the future, multi-functional acoustic metamaterials can be employed at a large scale for urban noise mitigation.

Furthermore, current acoustic metamaterials are explicitly designed for solving engineering problems while the aesthetic design of the designed metamaterials is ignored. This factor should be taken into consideration especially for their realization in architectural applications. 


\section{Conclusions}

In summary, acoustic metamaterials have shown a great deal of promise for meeting the present day demands for low-to-mid frequency noise mitigation in urban areas. Their unique nature like, multi-functionality and tunability make them robust and reliable for noise mitigation in a wide band gap, which include a variety of city noises such as traffic noise, construction noise, industrial noise, etc. Little progress has been made in the implementation of acoustic metamaterial-based noise barriers for real applications in the past few years. Based on the theoretical and laboratory-based experimental work, researchers have proved the significance of acoustic metamaterials. However, more diverse research is still required in terms of inexpensive fabrication techniques for mass production, appropriate material selection, noise testing at a large scale and long-term stability. Currently, the overall cost of acoustic metamaterials is likely to be high, but economy of scale can help to reduce the cost in the future. The existing solutions for low frequency sound mitigation use thick insulating materials or multiple layers of a material that are costly, and hence, metamaterials could prove competitive. Therefore, for industrial-scale implementation of acoustic metamaterials in the future, a robust cost evaluation is highly desirable. Huge scope of research lies in this field, wherein aspects like cost evaluation, cost comparison and material selection need to be considered. Last but not least, the concept of acoustic metamaterials should help in building a quieter society for living entities.

Funding: The first author would like to acknowledge the financial support from the Ministry of Education RSB Research Fellowship, Singapore.

Conflicts of Interest: The authors declare no conflict of interest.

\section{References}

1. Buss, R. United Nations Conference on the Human Environment (UNCHE). In Proceedings of the Stockholm Conference, Stockholm, Sweden, 5-16 June 1972.

2. Morillas, J.M.B.; Gozalo, G.R.; González, D.M.; Moraga, P.A.; Vílchez-Gómez, R. Noise Pollution and Urban Planning. Curr. Pollut. Rep. 2018, 4, 1-12. [CrossRef]

3. Walter Jensen, J.R.; Duke, N.S.; Edward, M.M. Noise Pollution and Abatement Act of 1972. In New Efforts Toward A Quieter Environment; Wiley: Hoboken, NJ, USA, 1975; Volume 13, pp. 45-46.

4. Bateni, H.; Vaizasatya, A.; Blaschak, M. The Effect of $80 \mathrm{~dB}$ Environmental Noise on Control of Posture in Healthy Young Adults. Hum. Factors Ergon. Manuf. 2013, 23, 213-221. [CrossRef]

5. World Health Organization. Environmental Noise Guidelines for the European Region; World Health Organization, Regional Office for Europe: Copenhagen, Denmark, 2018.

6. Stansfeld, S.A.; Matheson, M.P. Noise pollution: Non-auditory effects on health. Br. Med. Bull. 2003, 68, 243-257. [CrossRef] [PubMed]

7. Goines, L.; Hagler, L. Noise pollution: A modern plague. South. Med. J. 2007, 100, 287-294. [CrossRef] [PubMed]

8. Haralabidis, A.S.; Dimakopoulou, K.; Vigna-Taglianti, F.; Giampaolo, M.; Borgini, A.; Dudley, M.-L.; Pershagen, G.; Bluhm, G.; Houthuijs, D.; Babisch, W. Acute effects of night-time noise exposure on blood pressure in populations living near airports. Eur. Heart J. 2008, 29, 658-664. [CrossRef] [PubMed]

9. Dzhambov, A.M. Long-term noise exposure and the risk for type 2 diabetes: A meta-analysis. Noise Health 2015, 17, 23. [CrossRef] [PubMed]

10. Arenas, J.P.; Crocker, M.J. Recent trends in porous sound-absorbing materials. Sound Vibration 2010, 44, $12-18$.

11. Magrini, U.; Ricciardi, P. Surface sound acoustical absorption and application of panels composed of granular porous materials. Proc. Inter Noise 2000 2000, 27-30.

12. Frank, W.; Irregeher, J.F. Foam material sound absorption. United States Patent 4584232, 1986.

13. Haines, J.C.; Fay, R.M. Sound Absorption Laminate. WO 97/04445, 1995.

14. Pilaar, J.G. Inflatable Sound Attenuation System. 7992678, 9 August 2011.

15. Crocker, M.J. Handbook of Noise and Vibration Control; John Wiley \& Sons: Hoboken, NJ, USA, 2007.

16. Rossing, T.D. Springer Handbook of Acoustics; Springer: Berlin/Heidelberg, Germany, 2007. 
17. Cox, T.; d'Antonio, P. Acoustic Absorbers and Diffusers: Theory, Design and Application, 3rd ed.; CRC Press: Boca Raton, FL, USA; Taylor \& Francis Group, LLC: New York, NY, USA, 2017.

18. Yang, Z.; Dai, H.; Chan, N.; Ma, G.; Sheng, P. Acoustic metamaterial panels for sound attenuation in the 50-1000 Hz regime. Appl. Phys. Lett. 2010, 96, 041906. [CrossRef]

19. London, A. Transmission of reverberant sound through single walls. J. Res. Nat. Bur. Stand 1949, 42, 2. [CrossRef]

20. Mei, J.; Ma, G.; Yang, M.; Yang, Z.; Wen, W.; Sheng, P. Dark acoustic metamaterials as super absorbers for low-frequency sound. Nat. Commun. 2012, 3, 756. [CrossRef] [PubMed]

21. Yang, M.; Sheng, P. Sound Absorption Structures: From Porous Media to Acoustic Metamaterials. Annu. Rev. Mater. Res. 2017, 47, 83-114. [CrossRef]

22. Broner, N. The effects of low frequency noise on people? A review. J. Sound Vib. 1978, 58, 483-500. [CrossRef]

23. Yu, N.; Genevet, P.; Kats, M.A.; Aieta, F.; Tetienne, J.-P.; Capasso, F.; Gaburro, Z. Light propagation with phase discontinuities: Generalized laws of reflection and refraction. Science 2011, 334, 333-337. [CrossRef]

24. Maa, D.-Y. Potential of microperforated panel absorber. J. Acoust. Soc. Am. 1998, 104, 2861-2866. [CrossRef]

25. Song, G.Y.; Cheng, Q.; Huang, B.; Dong, H.Y.; Cui, T.J. Broadband fractal acoustic metamaterials for low-frequency sound attenuation. Appl. Phys. Lett. 2016, 109, 131901. [CrossRef]

26. Ma, G.; Sheng, P. Acoustic metamaterials: From local resonances to broad horizons. Sci. Adv. 2016, 2, e1501595. [CrossRef]

27. Fok, L.; Ambati, M.; Zhang, X. Acoustic metamaterials. MRS Bull. 2008, 33, 931-934. [CrossRef]

28. Cummer, S.A.; Christensen, J.; Alù, A. Controlling sound with acoustic metamaterials. Nature Rev. Mater. 2016, 1, 16001. [CrossRef]

29. Haberman, M.R.; Norris, A.N. Acoustic metamaterials. Phys. Today 2016, 12, 31-39. [CrossRef]

30. Huang, T.-Y.; Shen, C.; Jing, Y. Membrane-and plate-type acoustic metamaterials. J. Acoust. Soc. Am. 2016, 139, 3240-3250. [CrossRef] [PubMed]

31. Lee, S.H.; Wright, O.B. Origin of negative density and modulus in acoustic metamaterials. Phys. Rev. B 2016, 93, 024302. [CrossRef]

32. Ge, H.; Yang, M.; Ma, C.; Lu, M.-H.; Chen, Y.-F.; Fang, N.; Sheng, P. Breaking the barriers: Advances in acoustic functional materials. Natl. Sci. Rev. 2017, 5, 159-182. [CrossRef]

33. Lee, D.; Nguyen, D.M.; Rho, J. Acoustic wave science realized by metamaterials. Nano Converg. 2017, 4, 3. [CrossRef] [PubMed]

34. Assouar, B.; Liang, B.; Wu, Y.; Li, Y.; Cheng, J.-C.; Jing, Y. Acoustic metasurfaces. Nat. Rev. Mater. $2018,1$. [CrossRef]

35. Wu, Y.; Yang, M.; Sheng, P. Perspective: Acoustic metamaterials in transition. J. Appl. Phys. 2018, $123,090901$. [CrossRef]

36. Zangeneh-Nejad, F.; Fleury, R. Active times for acoustic metamaterials. Rev. Phys. 2019, 100031. [CrossRef]

37. Lee, J.; Kim, G.H.; Ha, C.S. Sound absorption properties of polyurethane/nano-silica nanocomposite foams. J. Appl. Polym. Sci. 2012, 123, 2384-2390. [CrossRef]

38. Yang, W.; Li, Y. Sound absorption performance of natural fibers and their composites. Sci. China Technol. Sci. 2012, 55, 2278-2283. [CrossRef]

39. Xue, B.; Li, R.; Deng, J.; Zhang, J. Sound absorption properties of microporous poly (vinyl formal) foams prepared by a two-step acetalization method. Ind. Eng. Chem. Res. 2016, 55, 3982-3989. [CrossRef]

40. Rajappan, S.; Bhaskaran, P.; Ravindran, P. An Insight into the Composite Materials for Passive Sound Absorption. J. Appl. Sci. 2017, 17, 339-356. [CrossRef]

41. Lim, Z.; Putra, A.; Nor, M.J.M.; Yaakob, M. Sound absorption performance of natural kenaf fibres. Appl. Acoust. 2018, 130, 107-114. [CrossRef]

42. Chen, C.; Du, Z.; Hu, G.; Yang, J. A low-frequency sound absorbing material with subwavelength thickness. Appl. Phys. Lett. 2017, 110, 221903. [CrossRef]

43. Huang, S.; Fang, X.; Wang, X.; Assouar, B.; Cheng, Q.; Li, Y. Acoustic perfect absorbers via spiral metasurfaces with embedded apertures. Appl. Phys. Lett. 2018, 113, 233501. [CrossRef]

44. Cai, X.; Guo, Q.; Hu, G.; Yang, J. Ultrathin low-frequency sound absorbing panels based on coplanar spiral tubes or coplanar Helmholtz resonators. Appl. Phys. Lett. 2014, 105, 121901. [CrossRef]

45. Ingard, U. On the theory and design of acoustic resonators. J. Acoust. Soc. Am. 1953, 25, 1037-1061. [CrossRef]

46. Li, Y.; Assouar, B.M. Acoustic metasurface-based perfect absorber with deep subwavelength thickness. Appl. Phys. Lett. 2016, 108, 063502. [CrossRef] 
47. Jiménez, N.; Huang, W.; Romero-García, V.; Pagneux, V.; Groby, J.-P. Ultra-thin metamaterial for perfect and quasi-omnidirectional sound absorption. Appl. Phys. Lett. 2016, 109, 121902. [CrossRef]

48. Tang, Y.; Ren, S.; Meng, H.; Xin, F.; Huang, L.; Chen, T.; Zhang, C.; Lu, T.J. Hybrid acoustic metamaterial as super absorber for broadband low-frequency sound. Sci. Rep. 2017, 7, 43340. [CrossRef]

49. Yang, Z.; Mei, J.; Yang, M.; Chan, N.; Sheng, P. Membrane-type acoustic metamaterial with negative dynamic mass. Phys. Rev. Lett. 2008, 101, 204301. [CrossRef]

50. Naify, C.J.; Chang, C.-M.; McKnight, G.; Nutt, S. Transmission loss and dynamic response of membrane-type locally resonant acoustic metamaterials. J. Appl. Phys. 2010, 108, 114905. [CrossRef]

51. Yang, M.; Ma, G.; Yang, Z.; Sheng, P. Coupled membranes with doubly negative mass density and bulk modulus. Phys. Rev. Lett. 2013, 110, 134301. [CrossRef] [PubMed]

52. Ang, L.Y.L.; Koh, Y.K.; Lee, H.P. Broadband sound transmission loss of a large-scale membrane-type acoustic metamaterial for low-frequency noise control. Appl. Phys. Lett. 2017, 111, 041903. [CrossRef]

53. Kumar, S.; Bhushan, P.; Prakash, O.; Bhattacharya, S. Double negative acoustic metastructure for attenuation of acoustic emissions. Appl. Phys. Lett. 2018, 112, 101905. [CrossRef]

54. Prakash, O.; Bhattacharya, S.; Kumar, S.; Bhushan, P. Composite Sound Absorption Panel Assembly. US 2019/0103089 A1, 2019.

55. Ma, F.; Huang, M.; Wu, J.H. Ultrathin lightweight plate-type acoustic metamaterials with positive lumped coupling resonant. J. Appl. Phys. 2017, 121, 015102. [CrossRef]

56. Ma, F.; Huang, M.; Xu, Y.; Wu, J.H. Bi-layer plate-type acoustic metamaterials with Willis coupling. J. Appl. Phys. 2018, 123, 035104. [CrossRef]

57. Ang, L.Y.L.; Koh, Y.K.; Lee, H.P. Plate-type acoustic metamaterial with cavities coupled via an orifice for enhanced sound transmission loss. Appl. Phys. Lett. 2018, 112, 051903. [CrossRef]

58. Ang, L.Y.L.; Koh, Y.K.; Lee, H.P. Plate-Type Acoustic Metamaterials: Experimental Evaluation of a Modular Large-Scale Design for Low-Frequency Noise Control. Acoustics 2019, 1, 354-368. [CrossRef]

59. Ang, L.Y.L.; Koh, Y.K.; Lee, H.P. Plate-type acoustic metamaterials: Evaluation of a large-scale design adopting modularity for customizable acoustical performance. Appl. Acoust. 2019, 149, 156-170. [CrossRef]

60. Kushwaha, M.S.; Halevi, P.; Dobrzynski, L.; Djafari-Rouhani, B. Acoustic band structure of periodic elastic composites. Phys. Rev. Lett. 1993, 71, 2022. [CrossRef]

61. Romero-García, V.; Picó, R.; Cebrecos, A.; Sánchez-Morcillo, V.J.; Staliunas, K. Enhancement of sound in chirped sonic crystals. Appl. Phys. Lett. 2013, 102, 091906. [CrossRef]

62. Liu, Z.; Zhang, X.; Mao, Y.; Zhu, Y.; Yang, Z.; Chan, C.; Sheng, P. Locally resonant sonic materials. Science 2000, 289, 1734-1736. [CrossRef] [PubMed]

63. Martínez-Sala, R.; Sancho, J.; Sánchez, J.V.; Gómez, V.; Llinares, J.; Meseguer, F. Sound attenuation by sculpture. Nature 1995, 378, 241. [CrossRef]

64. Romero-García, V.; Sánchez-Pérez, J.V.; Garcia-Raffi, L. Tunable wideband bandstop acoustic filter based on two-dimensional multiphysical phenomena periodic systems. J. Appl. Phys. 2011, 110, 014904. [CrossRef]

65. Romero-García, V.; Lagarrigue, C.; Groby, J.; Richoux, O.; Tournat, V. Tunable acoustic waveguides in periodic arrays made of rigid square-rod scatterers: Theory and experimental realization. J. Phys. D Appl. Phys. 2013, 46, 305108. [CrossRef]

66. Alagoz, S. A sonic crystal diode implementation with a triangular scatterer matrix. Appl. Acoust. 2014, 76, 402-406. [CrossRef]

67. Rubio, C.; Castiñeira-Ibáñez, S.; Uris, A.; Belmar, F.; Candelas, P. Numerical simulation and laboratory measurements on an open tunable acoustic barrier. Appl. Acoust. 2018, 141, 144-150. [CrossRef]

68. Jia, D.; Sun, H.-x.; Xia, J.-p.; Yuan, S.-q.; Liu, X.-j.; Zhang, C. Acoustic topological insulator by honeycomb sonic crystals with direct and indirect band gaps. New J. Phys. 2018, 20, 093027. [CrossRef]

69. Morandi, F.; Miniaci, M.; Marzani, A.; Barbaresi, L.; Garai, M. Standardised acoustic characterisation of sonic crystals noise barriers: Sound insulation and reflection properties. Appl. Acoust. 2016, 114, 294-306. [CrossRef]

70. Lee, H.M.; Tan, L.B.; Lim, K.M.; Lee, H.P. Experimental study of the acoustical performance of a sonic crystal window in a reverberant sound field. Build. Acoust. 2017, 24, 5-20. [CrossRef]

71. Lee, H.M.; Lim, K.M.; Lee, H.P. Reduction of Ceiling Fan Noise by Serrated Trailing Edge. Fluct. Noise Lett. 2018, 17, 1850026. [CrossRef] 
72. Lee, H.M.; Tan, L.B.; Lim, K.M.; Xie, J.; Lee, H.P. Field experiment of a sonic crystal window. Fluct. Noise Lett. 2018, 17, 1850032. [CrossRef]

73. Lee, H.M.; Haris, A.; Lim, K.M.; Xie, J.; Lee, H.P. Environmental Noise Mitigation by Plenum Window with Sonic Crystals and Jagged Flap. Fluct. Noise Lett. 2019, 18, 1950001. [CrossRef]

74. Cavalieri, T.; Cebrecos, A.; Groby, J.-P.; Chaufour, C.; Romero-García, V. Three-dimensional multiresonant lossy sonic crystal for broadband acoustic attenuation: Application to train noise reduction. Appl. Acoust. 2019, 146, 1-8. [CrossRef]

75. Schröder, M.R. Diffuse sound reflection by maximum-length sequences. J. Acoust. Soc. Am. 1975, 57, 149-150. [CrossRef]

76. Schroeder, M.R. Binaural dissimilarity and optimum ceilings for concert halls: More lateral sound diffusion. J. Acoust. Soc. Am. 1979, 65, 958-963. [CrossRef]

77. Zhu, Y.; Fan, X.; Liang, B.; Cheng, J.; Jing, Y. Ultrathin Acoustic Metasurface-Based Schroeder Diffuser. Phys. Rev. X 2017, 7, 021034. [CrossRef]

78. Jiménez, N.; Cox, T.J.; Romero-García, V.; Groby, J.-P. Metadiffusers: Deep-subwavelength sound diffusers. Sci. Rep. 2017, 7, 5389. [CrossRef]

79. Song, G.Y.; Cheng, Q.; Cui, T.J.; Jing, Y. Acoustic planar surface retroreflector. Phys. Rev. Mater. 2018, 2, 065201. [CrossRef]

80. Kim, S.-H.; Lee, S.-H. Air transparent soundproof window. AIP Adv. 2014, 4, 117123. [CrossRef]

81. Yu, X.; Lu, Z.; Liu, T.; Cheng, L.; Zhu, J.; Cui, F. Sound transmission through a periodic acoustic metamaterial grating. J. Sound Vib. 2019, 449, 140-156. [CrossRef]

82. Jung, J.W.; Kim, J.E.; Lee, J.W. Acoustic metamaterial panel for both fluid passage and broadband soundproofing in the audible frequency range. Appl. Phys. Lett. 2018, 112, 041903. [CrossRef]

83. Wu, X.; Au-Yeung, K.Y.; Li, X.; Roberts, R.C.; Tian, J.; Hu, C.; Huang, Y.; Wang, S.; Yang, Z.; Wen, W. Highefficiency ventilated metamaterial absorber at low frequency. Appl. Phys. Lett. 2018, 112, 103505. [CrossRef]

84. Shen, C.; Xie, Y.; Li, J.; Cummer, S.A.; Jing, Y. Acoustic metacages for sound shielding with steady air flow. J. Appl. Phys. 2018, 123, 124501. [CrossRef]

85. Li, L.J.; Zheng, B.; Zhong, L.M.; Yang, J.; Liang, B.; Cheng, J.C. Broadband compact acoustic absorber with high-efficiency ventilation performance. Appl. Phys. Lett. 2018, 113, 103501. [CrossRef]

86. Ghaffarivardavagh, R.; Nikolajczyk, J.; Anderson, S.; Zhang, X. Ultra-open acoustic metamaterial silencer based on Fano-like interference. Phys. Rev. B 2019, 99, 024302. [CrossRef]

87. Zhang, H.-1.; Zhu, Y.-f.; Liang, B.; Yang, J.; Yang, J.; Cheng, J.-c. Omnidirectional ventilated acoustic barrier. Appl. Phys. Lett. 2017, 111, 203502. [CrossRef]

88. Ge, Y.; Sun, H.-X.; Yuan, S.-Q.; Lai, Y. Broadband unidirectional and omnidirectional bidirectional acoustic insulation through an open window structure with a metasurface of ultrathin hooklike meta-atoms. Appl. Phys. Lett. 2018, 112, 243502. [CrossRef]

89. Ge, Y.; Sun, H.-X.; Yuan, S.-Q.; Lai, Y. Switchable omnidirectional acoustic insulation through open window structures with ultrathin metasurfaces. Phys. Rev. Mater. 2019, 3, 065203. [CrossRef]

90. Elford, D.; Chalmers, L.; Wilson, R. Acoustic attenuator. US Patent 20170263235 A1, 14 September 2017.

91. Acoustic screen with the NoiseTrap technology. Transformer Substation Noise Reduction Acoustic Attenuator. Available online: https://www.sonobex.com/portfolio-item/substation-transformer-noise/ (accessed on 16 June 2019).

92. Bishop-Moser, J.; Spadaccini, C.; Andres, C. Metamaterials Manufacturing: Pathway to Industrial Competitiveness; Metamaterials Manufacturing: Ann Arbor, MI, USA, 2018; pp. 1-42.

93. Babaee, S.; Viard, N.; Wang, P.; Fang, N.X.; Bertoldi, K. Harnessing deformation to switch on and off the propagation of sound. Adv. Mater. 2016, 28, 1631-1635. [CrossRef]

94. Yu, K.; Fang, N.X.; Huang, G.; Wang, Q. Magnetoactive Acoustic Metamaterials. Adv. Mater. 2018, 30, 1706348. [CrossRef] [PubMed]

95. Fan, S.-W.; Zhao, S.-D.; Chen, A.-L.; Wang, Y.-F.; Assouar, B.; Wang, Y.-S. Tunable Broadband Reflective Acoustic Metasurface. Phys. Rev. Appl. 2019, 11, 044038. [CrossRef]

96. Tian, Z.; Shen, C.; Li, J.; Reit, E.; Gu, Y.; Fu, H.; Cummer, S.A.; Huang, T.J. Programmable Acoustic Metasurfaces. Adv. Funct. Mater. 2019, 1808489. [CrossRef] [PubMed]

97. Harris, C.M. Absorption of sound in air versus humidity and temperature. J. Acoust. Soc. Am. 1966, 40, 148-159. [CrossRef] 
98. Bohn, D.A. Environmental effects on the speed of sound. In Proceedings of the Audio Engineering Society Convention 83, New York, NY, USA, 16-19 October 1987.

99. Qi, S.; Oudich, M.; Li, Y.; Assouar, B. Acoustic energy harvesting based on a planar acoustic metamaterial. Appl. Phys. Lett. 2016, 108, 263501. [CrossRef]

100. Oudich, M.; Li, Y. Tunable sub-wavelength acoustic energy harvesting with a metamaterial plate. J. Phys. D Appl. Phys. 2017, 50, 315104. [CrossRef]

101. Qi, S.; Assouar, B. Acoustic energy harvesting based on multilateral metasurfaces. Appl. Phys. Lett. 2017, 111, 243506. [CrossRef]

102. Mir, F.; Saadatzi, M.S.; Ahmed, R.U.; Banerjee, S. The possibility of harvesting electrical energy from industrial noise barriers using meta-wall bricks. In Proceedings of the Sensors and Smart Structures Technologies for Civil, Mechanical, and Aerospace Systems, Denver, CO, USA, 5-8 March 2018; p. 105982S.

(C) 2019 by the authors. Licensee MDPI, Basel, Switzerland. This article is an open access article distributed under the terms and conditions of the Creative Commons Attribution (CC BY) license (http://creativecommons.org/licenses/by/4.0/). 